\title{
Negritude e literatura negra como atos de conhecimento e de ação
}

\author{
Blackness and black literature as acts of knowledge and action \\ La negritud y la literatura negra como actos de conocimiento y acción \\ Cleusa Maria Gomes Graebin 1 \\ Universidade La Salle, Canoas, RS, Brasil.
} $\diamond$

RESENHA DA OBRA:

BERND, Zilá. Negritude e Literatura na América Latina. Porto Alegre: Cirkula, 2018. $175 \mathrm{p}$.

\begin{abstract}
RESUMO
Este trabalho consiste em uma resenha descritiva da segunda edição da obra Negritude e literatura na América Latina, da destacada pesquisadora sobre literatura comparada, Zilá Bernd. Mesmo após 30 anos de seu lançamento, a sua contribuição continua relevante no que tange às questões sobre negritude e sobre a construção de consciência negra nos espaços latino-americanos. Em que pese o crescimento quantitativo e qualitativo de produções literárias negras, ainda um grande contingente da população negra no Caribe e no Brasil não tem acesso a esse repertório cultural. Nesse sentido, a negritude, como afirmação de uma presença, e a literatura negra como atitude frente à atualidade da segregação no século XXI, se apresentam como evidências incontestáveis.
\end{abstract}

Palavras-chave: Literatura latino-americana. Literatura comparada. Negritude. Literatura negra. Poesia negra.

\begin{abstract}
This work consists of a descriptive review of the second edition of the book "Blackness and literature in Latin America", by prominent researcher on comparative literature, Zilá Bernd. Even after 30 years of the release, its contribution is still relevant, in regard to questions about blackness and the construction of black consciousness in Latin America. Despite the quantitative and qualitative growth of black literary productions, a large contingent of the Caribbean and Brazilian black population does not have access to this cultural repertoire. In this sense, blackness, as affirmation of a presence, and black literature as an attitude towards the actuality of the segregation in the 21 st century, presents itself as an undisputed evidence.
\end{abstract}

Keywords: Latin American literature. Comparative literature. Blackness. Black literature. Black poetry.

\section{RESUMEN}

Este trabajo consiste en una revisión descriptiva de la segunda edición de la obra "Negritud y literatura en América Latina", realizada por la destacada investigadora en literatura comparada, Zilá Bernd. Incluso, 30 años después de su liberación, su contribución sigue siendo relevante para los temas de la negritud y la construcción de la conciencia negra en los espacios latinoamericanos. A pesar del crecimiento cuantitativo y cualitativo de las producciones literarias negras, un gran contingente de la población negra en el Caribe y Brasil todavía no tiene acceso a este repertorio cultural. En este sentido, la negritud, como afirmación de una presencia, y la literatura negra como actitud hacia el estado actual de la segregación en el siglo XXI, se presentan como evidencia indiscutible.

Palabras clave: Literatura latinoamericana. Literatura comparada. Negritud. Literatura negra. Poesía negra. 
Esta obra, reeditada após trinta anos de sua primeira publicação, continua relevante tanto no campo de estudos comparados na literatura, ao tratar da análise sobre a construção de uma identidade negra na poesia caraíba, latino-americana e brasileira, como em termos de aportes fundamentais para discussões emergentes relativas à negritude nos países latino-americanos, ou seja, como homens e mulheres se apresentam e se assumem como negros e negras.

A obra traz a apresentação de seu editor - Mauro Meirelles - na qual salienta o pioneirismo de Zilá Bernd, na abordagem de uma literatura comparada latinoamericana com a presença de autores negros. A autora, por sua vez, esclarece que o esforço de reedição se relaciona ao crescimento da produção literária de afrodescendentes e o seu destaque no Brasil, bem como da necessidade da continuidade de discussões sobre a emergência e a afirmação da consciência negra como processo. Foi mantido o prefácio da primeira edição, escrito por Maximilien Laroche, no qual alude aos elementos que unem brasileiros e caraíbas de origem africana e às buscas de poetas negros de se expressarem enquanto tais.

A autora, no primeiro capítulo, "Uma literatura em busca de seu perfil", introduz os problemas que a levaram a pesquisar sobre a existência de uma literatura negra no Brasil, expressando-se, a partir da poesia, aos moldes do movimento de negritude caraíba, com textos nos quais há um sujeito de enunciação que se quer negro. Após discutir o conceito e o estado da arte sobre literatura negra, apresenta o recorte temporal (1922-1985) da produção poética a ser analisada. Apesar de reconhecer os textos teatrais desse período e a sua contribuição para a difusão de um ideário negro, Zilá Bernd, justifica a sua escolha por textos poéticos, tendo em vista a sua predominância. Também explicita o critério da escolha dos autores, concentradas no eixo Rio-São Paulo, respeitando a sua representatividade, isto é, com mais de duas ou três obras publicadas. Destaca a impossibilidade de fazer um levantamento exaustivo nos demais estados, tendo em vista a quantidade de autores e o tipo de análise a que se propôs. No entanto, traz o poeta sul-rio-grandense Oliveira Silveira, justificando a sua inclusão por sua expressiva produção e pela militância junto aos movimentos negros em Porto Alegre.

Ao final desse capítulo, a autora apresenta as suas hipóteses de pesquisa remetendo à existência, no Brasil, de produções literárias que não estão amparadas por instâncias de legitimação, que se articulam em torno de uma consciência negra, de uma construção identitária, com similaridade entre modelos caraíba e latino-americano.

O segundo capítulo, "Negritude e identidade", traz discussões sobre o conceito de negritude e de identidade. Quanto ao primeiro, a autora o coloca como interrogação, com recorte literário, não abandonando a sua dimensão de movimento político. Após tecer breves considerações sobre os aspectos da sua historicidade e o seu caráter de conceito plural, apresenta as diferentes críticas ao movimento que ao transformar-se em sua discursividade ideológica, dá especificidade e supremacia ao conceito de raça - uma personalidade específica. Zilá Bernd advoga uma negritude que coexista com outras consciências, como da americanidade, brasilidade etc., que partilhe determinadas situações históricas. Ainda em relação à negritude, a autora tece comentários sobre tendências apresentadas por movimentos negros no Brasil, destacando as releituras historiográficas e o surgimento de entidades como a Frente Negra Brasileira (1930) e o Teatro Experimental do Negro (1944), com o propósito de valorizar a contribuição da cultura africana na sociedade brasileira.

Quanto à questão da identidade, Zilá Bernd entende que, alienado de sua cultura de origem e cercado por valores de um mundo que o discrimina, a construção de identidade pelo negro é uma busca de autodefinição. A autora comenta que a poesia negra brasileira revela uma busca de identidade reflexiva, com dimensões de interioridade (visão de nós mesmos) e exterioridade (visão do outro sobre nós). O poeta negro traz em suas obras o desenraizamento, a busca por dimensões perdidas e a sua reconstrução como sujeito pertencente a uma comunidade.

No terceiro capítulo, "O processo de construção de uma identidade negra", a autora tece considerações sobre o transplante dos negros para as Américas e o seu processo de desculturação - perda dos traços elementares da cultura de origem - que se acentuam conforme o passar do tempo e a sua não inserção na construção de uma identidade nacional, tendo em vista a sua condição de escravizado ou de descendente. Mesmo após a formação dos estados nacionais latino-americanos, o negro convive entre dois mundos: o do branco - que o domina - e o seu próprio mundo - que não sabe o que representa. A autora remete à obra de Shakespeare, $A$ tempestade, na qual o personagem Próspero, o dominador, exaure o dominado, Calibã, retirando-lhe tudo, notadamente a consciência de si mesmo. O movimento de negritude se constitui em uma "vingança de Calibã", na busca de suas raízes, força vital, identidade, manifestada de diferentes maneiras.

Partindo dessa premissa, Zilá Bernd, faz considerações sobre as formas diretas e indiretas dos fenômenos relacionados às resistências negras nas Américas, tendo a literatura como um dos seus elementos. Discorre então, sobre as diferentes narrativas de escritores haitianos, desde o realismo maravilhoso aos textos das revistas manifesto, sobre os discursos historiográficos e literários latinoamericanos que se contrapõe aos dos dominadores; sobre a chamada "voz dos Trópicos", representada pela revista 
Tropiques, na qual Aimé Césaire, um dos construtores da negritude, passa a utilizar as expressões poesia negra e poeta negro e como um porta-voz e intérprete do destino de sua comunidade. Esse autor, discute Bernd, é o criador, em linhas gerais, de uma estética da poesia negra americana.

Ainda nesse capítulo, a autora traz considerações sobre o discurso da negritude nos escritos de poetas caraíbas, apontando o fio que os aproxima, ou seja, o inventário de um mundo que lhes dá proximidade e três categorias que os reúnem, a saber: os ritmos e sonoridades, a lei da dominação e a lei da reversão de valores. Continuando as suas reflexões, apresenta tendências alternativas no Caribe, nos anos 1980. Finaliza o capítulo, abordando a literatura negra em sua reapropriação em diferentes contextos e espaços culturais (Uruguai, Equador, Peru, Colômbia), a sua permanente busca de identidade, falando a receptores que passam por diferentes formas de racismo. A autora conclui com comentários sobre o que chama de negritude sintetizada.

O quarto capítulo, "A construção de uma identidade negra na poesia brasileira", inicia apresentando os pressupostos e autores que utiliza para a avaliação do seu corpus que intitula literatura negra, reconhecendo a variedade de denominações que essa recebe. Caracterizam essa literatura as suas raízes afro, elementos que podem ser observados no seu discurso, território supranacional de circulação e comunidade de destino composta pelos autores e receptores.

A autora explicita o desenho do perfil da poesia negra no Brasil, como literatura de resistência, remetendo ao surgimento e constituição de uma imprensa negra, de associações e do teatro negro. Na resistência negra, trazendo o exemplo de Solano Trindade, compreende uma linhagem de poetas que trazem nas suas obras uma pertença ao solo americano, a um conceito integrado de América e suas poesias se constituindo como o lugar do oprimido de qualquer raça.

$\mathrm{Na}$ sequência, trata sobre a ambiguidade que aparece em alguns autores, uma consciência dilacerada entre dois mundos - a assimilação de valores dos brancos e a perda dos valores dos negros -, percebida em romancistas e poetas negros, evidenciando uma identidade parcelar, vivendo entre o mundo do dia e da noite, entre o sofrimento e o enaltecimento.

Outro discurso poético é aquele que se reveste de descrença em propostas ideológicas salvadoras (marxismo, catolicismo), que deram substrato a alguns autores. Aquele substitui o momento de espera pela redenção pelo da cólera, programa de luta, de mobilização, de engajamento. Não mais o poeta como a voz da sua comunidade, mas inserido no próprio combate que esta trava pelo seu reconhecimento.
A autora dá destaque para a negritude e a gauchidade representadas por Oliveira Silveira, em cuja obra extensa integra a negritude latino-americana e um regionalismo que aparece com o repertório do falar gauchesco, vertente por ele chamada de afro-gaúcha. Ao finalizar esse capítulo, Zilá Bernd aponta constantes discursivas que conferem unidade aos textos da poesia negra: a sua existência fora da legitimidade do que se convenciona chamar de campo literário instituído, emergência do eu enunciador e sua gênese, a construção de uma cosmogonia, de um universo negro na América, a ordenação de nova ordem simbólica, a reversão dos valores, a avaliação do outro e a tendência à teorização no paratexto. A autora aponta para a reapropriação pelo poeta negro de espaço existencial próprio, em processo dinâmico de construção identitária e literatura como laboratório de resgate de vazios existenciais.

No quinto capítulo, "Poesia negra: um discurso a muitas vozes", Zilá Bernd finaliza a obra, discutindo a articulação entre os discursos poéticos brasileiro e latino-americano, postos em relação com traços comuns que remetem ao negro no processo de reconhecimento de si, de enraizamento, fazendo a sua própria leitura e interpretação do mundo, no que chama de território reencontrado.

Recebido em: 8/8/2019.

Aprovado em: 29/10/2019.

Publicado em: 21/12/2019.

Autora:

Cleusa Maria Gomes Graebin

Doutora, Professora na Universidade La Salle, Canoas, RS, Brasil.

Orcid: http://orcid.org/0000-0002-2919-5687

E-mail: cleusa.graebin@unilasalle.edu.br

Endereço: Universidade La Salle

Av. Victor Barreto, 2288 - Centro

92010-000, Canoas, RS, Brasil 